УДК 550.4.02

\title{
МИКРОЭЛЕМЕНТНЫЙ СОСТАВ ВОДНЫХ ЭКСТРАКТОВ НЕКОТОРЫХ ОБРАЗЦОВ ДИАТОМИТОВ И ЛИДИТОВ КАРЕЛИИ
}

\author{
Феоктистов Владимир Михайлович1, \\ feoktistov@petrsu.ru \\ Медведев Павел Владимирович1,2, \\ pmedved@krc.karelia.ru \\ 1 Петрозаводский государственный университет, \\ Россия, Республика Карелия, 185910, г. Петрозаводск, пр. Ленина, 33. \\ 2 Карельский научный центр РАН, \\ Россия, Республика Карелия, 185910, г. Петрозаводск, ул. Пушкинская, 11.
}

\begin{abstract}
Актуальность исследования обусловлена необходимостью получения достоверной информации об элементном составе водных экстрактов диатомитов и лидитов. В настоящее время диатомиты используются в различных отраслях промышленности, в том числе медицинской и фармацевтической. Однако детального изучения состава их водных экстрактов практически не проводилось.

Цель: изучить микроэлементный состав водных экстрактов нескольких образцов диатомитов и лидитов.

Объекты: три образца диатомитов и два образца лидитов территории Республики Карелия.

Методика: лабораторный эксперимент, водная экстракция, масс-спектрометрия с индуктивно-связанной плазмой (ICP MS).

Результаты. Изучен элементный состав водных экстрактов нескольких образцов диатомитов и лидитов территории Республики Карелия методом ICP MS. Во всех исследованных экстрактах образцов диатомитов и лидитов преобладающими элементами являются $\mathrm{Mg}, \mathrm{Na}, \mathrm{Ca}, \mathrm{K}$ и Al (до нескольких тысяч мке/л). Экстракты образцов диатомитов имеют однородньй состав. Максимальные содержания в них других, наиболее значимых, элементов составляли: $P$ - до 650, Fe - до 1700 (образеи № 1) и Mn - до 3300 (образец № 3) мке/л. Концентрации в диапазоне от 10 до 100 мк2/л характерны для ряда элементов (Li, B, $\mathrm{Ti}$, Cr, Co, Ni, Cu, Zn, Sr, Y, Zr u Ba) в экстрактах всех образцов диатомитов. Экстракты образцов диатомитов № 1 и 2 имели максимальные концентрации легких редкоземельных элементов (РЗЭ): Nd (до 247), Ce (до 230), La (до 156 мк2/л). Химический состав экстрактов образцов лидитов заметно отличался, как между собой, так и от экстрактов диатомитов. Кислая среда (pH 4,5-4,6) экстракта образца № 4 способствовала накоплению ряда элементов: $\mathrm{Ni}, \mathrm{Sr}, \mathrm{Be}, \mathrm{Mn}, \mathrm{U}, \mathrm{Tl}, \mathrm{u}$ особенно V, Co, Cu, Zn, Y, Ва. В то же время в экстракте образца № 5 в слабощелочных условиях (рH 7,4-7,5) наблюдались максимальные концентрации Mo, W, Zr, Hf. В исследованных экстрактах образцах диатомитов и лидита № 4 концентрации Al, Mn, $\mathrm{Fe}, \mathrm{Co}, \mathrm{Ni}, \mathrm{Cu}$, Zn превышали значения предельно допустимых концентраций (ПДК) рыбохозяйственных водоемов. Водные экстракты образцов диатомитов показали значительное содержание элементов, которые могут оказать влияние на формирование состава маломинерализованных карельских вод. При этом содержание ряда полезных для развития растений микроэлементов (Са, $\mathrm{Mg}$, $K, P, \mathrm{Cu}, \mathrm{Zn}, \mathrm{V}, \mathrm{Mn}, \mathrm{Sr}, \mathrm{Y}, \mathrm{Zr}$ ) предполагает возможность их использования как «мягких» удобрений (или добавок к минеральным удобрениям).
\end{abstract}

Ключевые слова:

Диатомит, лидит, микроэлементный состав, водные экстракты, Карелия, палеопротерозой, голоцен.

\section{Введение}

Диатомиты находят широкое применение в разных промышленных сферах как в России $[1,2]$, так и за рубежом [3, 4]. Например, производство фильтровальных порошков, красок и лаков, высококачественной бумаги, тонких абразивов, высокопрочной резины. Также диатомиты можно использовать в медицинской, фармакологической и пищевой промышленности как полезные композитные и нанокомпозитные материалы, биостимуляторы, адсорбенты, кондиционные добавки [5-10].

Диатомиты Карелии достаточно хорошо изучены геологически [1]. Эти озерные отложения голоценового возраста в основном состоят из опаловых скелетов одноклеточных диатомовых водорослей. В озёрах диатомиты залегают на глубине до 7 м, образуя слои мощностью 2-4 м. Ещё в 30-х гг. прошлого века были проведены технологические испытания карельских диатомитов, показавшие их высокое качество $[11,12]$.
Химический состав диатомитов определяется массовой долей оксидов основных элементов ( $\mathrm{Si}, \mathrm{Al}, \mathrm{Fe}$, $\mathrm{Ca}, \mathrm{Na}, \mathrm{K}$ и $\mathrm{P}_{2} \mathrm{O}_{5}$ ), измеренной после прокаливании. В природных диатомитах содержание кремнезёма составляет от 50 до $70 \%$. Количество оксидов кальция, натрия и калия около 1 \%, фосфора - 0,2 \%. Содержание оксидов алюминия и железа колеблется от 0,8 до 12, а органики - от 0,17 до $45 \%$. По химическому составу диатомиты Карелии сходны с диатомитами Кольского полуострова и Финляндии [13], а от диатомитов Ленинградской области отличаются отсутствием примеси песка [1].

Известно также, что биогенный кремнезем осадочных пород содержит большое количество аморфного кремнезема (в диатомитах - до 95 \% [14]), который, обладая достаточно высокой растворимостью, может участвовать в формировании состава природных вод [15].

Лидиты Карелии относятся к хемогенным породам, образовавшимся в морской воде приблизительно 
2 млрд лет назад $[16,17]$. Они представляют интерес для промышленности как огнеупорный материал, причем без предварительной подготовки, а также как возможная основа для получения катализаторов [18]. Это черные матовые афанитового сложения кремнистые породы с характерным раковистым изломом. Твердость лидитов около 7 единиц по шкале Мооса, удель-

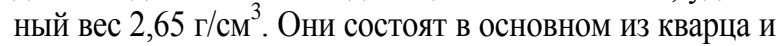
углерода, в виде шунгитового вещества, в небольшом количестве присутствует серицит (таблица) [19]. Лидиты образовались из гелеподобных, водонасыщенных осадков, что подтверждается мелкосгустковой структурой, характерной для опок и фтанитоидов [20].

Таблица. Химический состав лидитов, п. Шуньга, Республика Карелия, масс. \%

Table. Chemical composition of lydites, Shunga, Republic of Karelia, wt. \%

\begin{tabular}{|c|c|c|c|c|}
\hline Показатель/Parameter & $\mathrm{SiO}_{2}$ & $\mathrm{Al}_{2} \mathrm{O}_{3}$ & $\mathrm{Fe}_{2} \mathrm{O}_{3}$ & $\begin{array}{c}\text { Потери при } \\
\text { прокаливании } \\
\text { Loss on ignition }\end{array}$ \\
\hline $\begin{array}{c}\text { Среднее из10 проб } \\
\text { Average of 10 samples }\end{array}$ & 95,4 & 0,45 & 0,20 & 3,85 \\
\hline
\end{tabular}

В Карелии на территории Заонежского полуострова лидиты стратиграфически приурочены к кровле первой и второй пачек верхнезаонежской подсвиты, где формируют 4-10 метровые пласты [21]. Они входят в состав так называемого «лидит-шунгит-доломитового комплекса», известного во многих разрезах: с. Шуньга, д. Тетюгино, п. Кяппесельга, д. Мунозеро, оз. Яндомозеро, п. В. Губа, оз. Керацкое и др. [22].

Для большинства отмеченных направлений использования диатомитов и лидитов необходимо иметь информацию о более полном химическом составе как самих диатомитов, так и их водных экстрактов.

Целью нашего исследования являлось изучение микрокомпонентного состава водных экстрактов отдельных образцов диатомитов и лидитов Карелии с использованием масс-спектрометрического метода с индуктивно связанной плазмой (ICP MS) и оценка их возможного влияния на качество воды.

\section{Объекты и метод исследования}

В качестве объектов исследования выбраны три образца диатомитов - Д0016 (ламба Тедрилампи), образец № 1; ДТ-39 (месторождение Кяпели, пос. Тунгозеро), образец № 2; ДР 80 (оз. Видалампи, пос. Тикша), образец № 3 и два образца лидитов - ЛТ 20 (дер. Тетюгино), образец № 4 и ЛШ (п. Шуньга), образец № 5 (рисунок).

Подготовку проб водных экстрактов изучаемых образцов диатомитов и лидитов проводили по следующей схеме: 20 г порошкообразного образца $(0,4<\mathrm{d}<100$ микрон) помещали в пластиковую бутылку объемом $500 \mathrm{~cm}^{3}$, заливали $200 \mathrm{~cm}^{3}$ деионированной воды и настаивали при комнатной температуре, при периодическом перемешивании и естественном освещении в течение 10 суток [23]. Измерение химических показателей полученных водных экстрактов проводили через 1, 3 и 10 суток настаивания, после центрифугирования проб (относительное ускорение центрифуги - $4000 \mathrm{~g}$ ). В данной работе рассматриваются результаты исследования водных экстрактов диатомитов и лидитов за весь период наблюдений.

Экстракты образцов размолотых диатомитов и лидитов исследованы методом ICP MS в Аналитическом центре Института геологии Карельского НЦ РАН. Концентрации химических элементов определялись на квадрупольном масс-спектрометре $\mathrm{X}$ SERIES 2. Для контроля точности определения элементов использовали стандарты Trace Metals in Water -IV-STOCK-1643 и NIST 612. Содержание растворенного кремния определяли спектрофотометрическим методом в виде желтой формы молибденокремниевой кислоты [24], рН растворов измеряли потенциометрическим методом [25].

\section{Результаты исследования}

Водные экстракты трех образцов диатомитов имели слабокислую реакцию среды в течение всего опыта, на десятые сутки она составляла 5,8-5,9 ед. $\mathrm{pH}$. Величины pH экстрактов образцов лидитов существенно различались между собой, образец № 4 во время всей экспозиции имел значения 4,5-4,6, тогда как экстракт образца № 5 был слабощелочным ( $\mathrm{pH}=7,36-7,50)$.

По результатам определения 54 химических элементов в водных экстрактах диатомитов преобладающими ионами являются, как правило, $\mathrm{Mg}, \mathrm{Na}, \mathrm{Ca}, \mathrm{K}$ и $\mathrm{Al}$, их концентрации составляли до нескольких тысяч мкг/л. В отдельных образцах диатомитов также активно извлекаются в водную фазу фосфор, железо и марганец, максимальные концентрации которых составляли: Р - до 700, $\mathrm{Fe}$ - до 1700 (образец № 1), $\mathrm{Al}$ - до 1100 (образец № 2), Mn - до 3300 (образец № 3) мкг/л. Образцы экстрактов диатомитов № 1 и 2 имели максимальные концентрации легких редкоземельных элементов (РЗЭ): Nd (до 247 мкг/л), Се (до 230 мкг/л), La (до 156 мкг/л). Концентрации в диапазоне от 10 до 100 мкг/л имели $\mathrm{V}, \mathrm{Mn}$ и $\mathrm{Zr}$ в экстрактах диатомитов № 1 и 2, а также $\mathrm{Cu}, \mathrm{Zn}, \mathrm{Sr}, \mathrm{Y}$ и $\mathrm{Ba}$ - во всех экстрактах исследованных диатомитов. Содержание остальных элементов было заметно ниже и составляло от нескольких сотых до нескольких мкг/л.

Водные экстракты диатомитов всех образцов на десятый день экстракции имели очень близкий между собой химический состав, несмотря на то, что после первого дня опыта концентрации ряда элементов существенно различались. Например, на первые сутки содержание $\mathrm{Li}$ в образце № 1 было 47,0, в образце № 2 - 5,22 мкг/л, а через 10 дней - 32,2 и 32,8 мкг/л, соответственно. Концентрация Ва в образце диатомита № 1 после первого дня составляла 39,0, в образце № 2 - 130 мкг/л, а после десятого дня - 33,2 и 30,8 мкг/л, соответственно, и т. д.

Водный экстракт диатомита № 3 отличается от экстрактов диатомитов № 1 и 2 повышенным содержанием ряда элементов: Со (в 14 ра3), Mn (10), U (4) и пониженными концентрациями $\mathrm{Zr}$ (в 8 раз) и $\mathrm{Ag}, \mathrm{Y}$ и $\mathrm{Cr}$ (в 3-4 раза), а также легких лантаноидов ( $\mathrm{La}, \mathrm{Ce}, \mathrm{Pr}, \mathrm{Nd})$ в 4-5 раз и тяжелых лантаноидов (от Sm до Lu) - в 2-3 раза. 


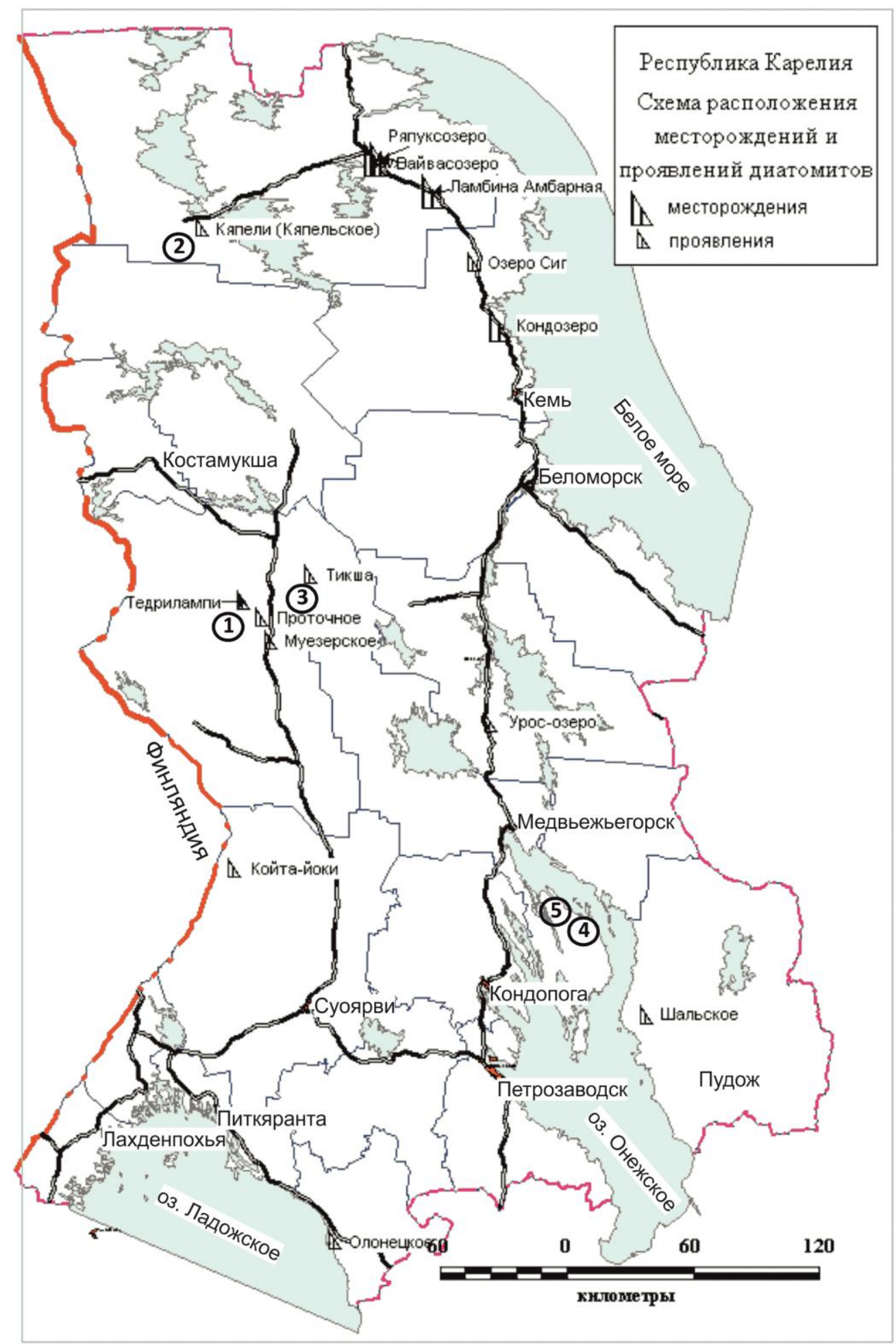

Рисунок. Места отбора проб диатомитов: 1 - Тедрилампи, 2 - Кяпели, 3 - Тикиа; и лидитов: 4 - Тетюгино, 5 Шуньга. Карта с сайта [23]

Figure. $\quad$ Sampling sites of diatomites: 1-Tedrilampi, 2-Kyapeli, 3-Tiksha; and lydites: 4-Tetyugino, 5-Shunga. The map adopted from [23]

Для экстракта образца лидита № 4 преобладающим ионом является $\mathrm{K}$, высокие содержания отмечены для $\mathrm{Mg}, \mathrm{Na}, \mathrm{Ca}$ и $\mathrm{Al}$. Для лидита № 5 ряд элементов с максимальными концентрациями выглядит так: $\mathrm{Mg}, \mathrm{K}$ и Na. Содержание $\mathrm{Al}$ было здесь на порядок меньше, чем во всех других образцах, а концентрации ряда элементов (Ca, P, Zn, Ba, Be и Th) незначительно превышали значения контрольного образца исходной воды, т. е. эти элементы практически не извлекались в водную фазу. В целом выщелачивание элементов в водную фазу из лидитов было ниже, чем у диатомитов. 
Элементный состав экстрактов лидитов существенно различается между собой, как и состав преобладающих ионов. В экстракте образца лидита № 4 содержание ряда металлов в десятки $(\mathrm{Sr}, \mathrm{Mn}, \mathrm{U})$ и сотни раз (Be, $\mathrm{Fe}, \mathrm{Co}, \mathrm{Ni}, \mathrm{Cu}, \mathrm{Zn}, \mathrm{Y}, \mathrm{Ba}, \mathrm{Tl})$ превышает их значения образца № 5. По-видимому, этому способствовала кислая среда этого экстракта (рH 4,5-4,6). В то же время для ряда элементов наблюдается обратная картина, концентрация $\mathrm{V}, \mathrm{Mo}, \mathrm{W}, \mathrm{Zr}, \mathrm{Hf}$ в экстракте лидита № 4 значительно меньше, чем в № 5 , что свидетельствует о повышенной миграционной активности этих элементов в слабощелочных условиях (pH 7,4-7,5) этого образца. Ряд элементов для обоих образцов лидитов имели близкие значения (например, P, Cr, Sn, Sb, Te, Ta, Bi, Th).

Содержание легких P3Э ( $\mathrm{La}, \mathrm{Ce}, \mathrm{Nd}, \mathrm{Pr}, \mathrm{Sm})$ во всех образцах экстрактов диатомитов, особенно в образцах № 1 и 2, превышало значения для лидитов приблизительно в 4-5 раза. По-видимому, такое различие связано с условиями формирования диатомитов и лидитов. Диатомиты формировались в пресной воде маленьких озер послеледниковых ландшафтов (8-10 тыс. лет назад). Кислые докембрийские породы Карелии обогащены диоксидом кремния, а ландшафтные условия способствовали его химическому выветриванию и поступлению с подземным стоком в озера [27]. В озерах установились гидрохимические условия с уровнем минерализации и содержанием кремнекислоты благоприятными для формирования кремнистых скелетов диатомей [28]. При этом обнаружение повышенных концентраций легких РЗЭ в диатомитах свидетельствует об их интенсивном контакте с грунтовыми водами гранитогнейсовых коренных пород. Среди образцов лидитов РЗЭ явно преобладали в экстракте образца № 4.

В водных экстрактах исследованных образцов диатомитов и лидитов для ряда элементов отмечено превышение значений ПДК рыбохозяйственных водоемов [29]. Содержание $\mathrm{Al}$ и $\mathrm{Mn}$ во всех образцах значительно превышало «норму», в образце диатомита № 3 превышение для $\mathrm{Al}$ и $\mathrm{Mn}$ было в 30 и 200 раз, соответственно. Переходные элементы ( $\mathrm{Fe}, \mathrm{Ni}, \mathrm{Cu}, \mathrm{Zn})$ показали постоянное превышение «нормы» ПДК в экстрактах диатомитов и образца лидита № 4. Наибольшие превышения, отмеченные для этого образца, составили для $\mathrm{Mn}-60, \mathrm{Fe}-90, \mathrm{Cu}-930, \mathrm{Ni}-28$ и $\mathrm{Zn}-40$ раз. В экстракте лидита № 5 существенные превышения значений ПДК обнаружено для V и Мо.

\section{СПИСОК ЛИТЕРАТУРЫ}

1. Демидов И.Н., Шелехова Т.С. Диатомиты Карелии (особенности формирования, распространения, перспективы использования). - Петрозаводск: Карельский НЦ РАН, 2006. - 89 с.

2. Смирнов П.В. Результаты комплексных исследований вещественного состава диатомитов Ирбитского месторождения // Известия Томского политехнического университета. Инжиниринг георесурсов. - 2016. - Т. 327. - № 6. - С. 93-104.

3. Mechanical and slow-released property of poly(acrylamide) hydrogel reinforced by diatomite / J. Lu, B. Sun, J. Jin, W. Jiang // Materials Science and Engineering. - 2019. - V. 99. - P. 315-321.

4. Wu W.-L., Chen Z. Modified-diatomite reinforced rubbers // Materials Letters. - 2017. - V. 209. - P. 159-162.

\section{Заключение}

Изучен элементный состав водных экстрактов нескольких образцов диатомитов и лидитов Карелии методом ICP MS. Во всех исследованных экстрактах образцов диатомитов и лидитов преобладающими элементами являются $\mathrm{Mg}, \mathrm{Na}, \mathrm{Ca}, \mathrm{K}$ и $\mathrm{Al}$ (до нескольких тысяч мкг/л). Экстракты образцов диатомитов имеют однородный состав. Максимальные содержания в них других, наиболее значимых, элементов составляли: $\mathrm{P}$ - до 650, $\mathrm{Fe}$ - до 1700 (образец № 1) и $\mathrm{Mn}$ - до 3300 (образец № 3) мкг/л. Концентрации в диапазоне от 10 до 100 мкг/л характерны для ряда элементов ( $\mathrm{Li}, \mathrm{B}, \mathrm{Ti}, \mathrm{Cr}, \mathrm{Co}, \mathrm{Ni}, \mathrm{Cu}, \mathrm{Zn}, \mathrm{Sr}, \mathrm{Y}, \mathrm{Zr}$ и $\mathrm{Ba}$ ) всех экстрактов образцов диатомитов. Экстракты образцов диатомитов № 1 и 2 имели максимальные концентрации легких РЗЭ: Nd (до 247), Се (до 230), $\mathrm{La}$ (до 156 мкг/л).

Химический состав экстрактов образцов лидитов заметно отличался, как между собой, так и от состава диатомитов. Кислая среда (pH 4,5-4,6) экстракта образца № 4 способствовала накоплению ряда элементов $\mathrm{Sr}, \mathrm{Mn}, \mathrm{U}$ и особенно $\mathrm{Be}, \mathrm{Fe}, \mathrm{Co}, \mathrm{Ni}, \mathrm{Cu}, \mathrm{Zn}, \mathrm{Y}, \mathrm{Ba}$, Tl. В то же время в экстракте образца № 5, в слабощелочных условиях (pH 7,4-7,5), наблюдались максимальные концентрации $\mathrm{V}, \mathrm{Mo}, \mathrm{W}, \mathrm{Zr}$ и $\mathrm{Hf}$.

Во всех исследованных экстрактах образцах диатомитов и лидитов концентрации $\mathrm{Al}$ и $\mathrm{Mn}$ превышали значения ПДК рыбохозяйственных водоемов. Превышение «нормы» ПДК показали также переходные элементы $(\mathrm{Fe}, \mathrm{Co}, \mathrm{Ni}, \mathrm{Cu}, \mathrm{Zn})$ в экстрактах всех диатомитов и образца лидита № 4 , а также $\mathrm{V}$ и Мо в образце лидита № 5 .

Исследование водных экстрактов диатомитов и лидитов показало, что при определенных условиях они могут оказать существенное влияние на состав слабоминерализованных карельских вод. При этом содержание в них ряда полезных для развития растений элементов (Mg, Ca, K, Cu, Zn, V, Mn, Sr, Y и Zr) предполагает возможность их использования как «мягких» удобрений (или добавок к минеральным удобрениям).

Авторы выражают благодарность старшему научному сотруднику Института геологии КарНЦ РАН Т.С. Шелеховой за любезно предоставленные для исследования образиь диатомитов и ведущему физику Аналитического центра Института геологии КарНЦ РАН А.С. Парамонову за выполнение анализов методом ICP MS.

Исследования выполнены в рамках государственного задания Института геологии КарНЦ РАН.

5. Hydrated lanthanum oxide-modified diatomite as highly efficient adsorbent for low-concentration phosphate removal from secondary effluents / Y. Wu, X. Li, Q. Yang, D. Wang, X. Huang // Journal of Environmental Management. - 2019. - V. 231. - P. 370-379.

6. Thermal and microstructural properties of paraffin/diatomite co posite / S. Benayache, S. Alleg, A. Mebrek, J.J. Suñol // Vacuum. - 2018. - V. 157. - P. 136-144.

7. Experimental study on preparation of lauric acid/microwavemodified diatomite phase change material composites / Y. Konuklu, O. Ersoy, F. Erzin, Y.Ö. Toraman // Solar Energy Materials and Solar Cells. - 2019. - V. 194. - P. 89-94.

8. Nanocomposites CoPt-x/Diatomite-C as oxygen reversible electrocatalysts for zinc-air batteries: Diatomite boosted the catalytic 
activity and durability / K. Wang, Z. Tang, W. Wu, P. Xi, Sh. Chen // Electrochimica Acta. - 2018. - V. 284. - P. 119-127.

9. Novel hierarchically porous allophane/diatomite nanocomposite for benzene adsorption / L. Deng, P. Du, W. Yu, P. Yuan, J. Zhou // Applied Clay Science. - 2019. - V. 168. - P. 155-163.

10. Diatomite supported by $\mathrm{CaO} / \mathrm{MgO}$ nanocomposite as heterogeneous catalyst for biodiesel production from waste cooking oil / A.M. Rabie, M. Shaban, M.R. Abukhadra, R. Hosny, N.A. Negm // Journal of Molecular Liquids. - 2019. - V. 279. - P. 224-231.

11. Марков К.К. Диатомит // Полезные ископаемые Ленинградской области и Карельской АССР. Справочник. Ч. ІІ. - Ленинград: Горгеонефтьиздат, 1933. - С. 67-85.

12. Варданянц П.А. Диатомиты северной Карелии // Материалы по геологии и полезным ископаемым Карелии. - М.; Л.: ОНТИ НКТП СССР, 1936. - С. 83-93.

13. Gronlund T. Diatomite deposit in the basin of Lake Soijarvi, central Finland // Bull. Geo.Soc. Finland. - 1986. - V. 58. - P. 2. P. $35-45$.

14. Дистанов У.Г. Опал-кристобалитовые породы // Минеральное сырье. Справочник. - М.: ЗАО «Геоинформмарк», 1998. - 28 с.

15. Влияние опал-кристаболитовых пород на содержание растворимых форм кремнезема в природных водах / Е.Н. Офицеров, Г.К. Рябов, Ю.А. Убаськина, А.Б. Климовский, Е.Г. Фетюхина // Известия Самарского научного центра РАН. - 2011. - Т. 13. № 4 (2). - C. 558-563.

16. Karelian shungite - an indication of 2,0-Ga-old metamorphosed oil-shale and generation of petroleum: geology, lithology and geochemistry / V.A. Melezhik, A.E. Fallick, M.M. Filippov, O. Larsen // Earth Sci. Rev. - 1999. - V. 47. - P. 1-40.

17. Giant Palaeoproterozoic petrified oil field in the Onega Basin / V.A. Melezhik, A.E. Fallick, M.M. Filippov, Y.E. Deines, A.E. Črne, A. Lepland, A.T. Brasier, H. Strauss // Reading the Archive of Earth's Oxygenation. V. 3. Global Events and the Fennoscandian Arctic Russia - Drilling Early Earth Project / Eds.V.A. Melezhik, A.R. Prave, A.E. Fallick, L.R. Kump, H. Strauss, A. Lepland, E.J. Hanski. - Heidelberg, New York, Dordrecht, London: Springer, 2013. - P. 1202-1212.

18. Виноградов Н.В. Возможность модификации поверхности минерала лидита переходными металлами // Проблемы геологии и освоения недр: Труды XIX Международного симпозиума имени академика М.А. Усова студентов и молодых ученых. -
Томск: Изд-во Томского политехнического университета, 2015. - T. 2. - C. 250-252.

19. Атлас текстур и структур шунгитоносных пород Онежского синклинали / под ред. М.М. Филиппова, В.А. Мележика. Петрозаводск: Карельский НЦ РАН, 2007. - 80 с.

20. Хворова И.В., Дмитрик А.П. Микроструктуры кремнистых пород. - М.: Наука, 1972. -170 с.

21. Melezhik V.A., Filippov M.M., Romashkin A.E. A giant Palaeoproterozoic deposit of shungite in NW Russia: genesis and practical applications // Ore Geol. Rev. - 2004. - V. 24. - P. 135-154.

22. Филиппов М.М., Дейнес Ю.Е. Субпластовый тип месторождений шунгитов Карелии. - Петрозаводск: КарНЦ РАН, 2018. $-261 \mathrm{c}$

23. Диатомит // Управление недропользования. 2014. URL: http://nedrark.karelia.ru/mnia/diatomit_karelia.htm (дата обращения 15.01.2020).

24. Особенности химического состава природных кремневых конкреций и их водных экстрактов / В.М. Феоктистов, В.В. Вапиров, С.Ю. Чаженгина, С.А. Светов // Экологическая химия. - 2019. - № 28 (1) - - С. 10-21.

25. Руководящий документ РД 52.24.433-2005. Массовая концентрация кремния в поверхностных водах суши. Методика выполнение измерений фотометрическим методом в виде желтой формы молибдокремниевой кислоты. - Ростов-на-Дону: Изд-во Гидрохимического института, 2005. - 15 с.

26. Руководящий документ РД 52.24.495-2005. Водородный показатель и удельная электрическая проводимость вод. Методика выполнения измерений электрохимическим методом. - Ростов-на-Дону: Изд-во Гидрохимического института, 2005. $10 \mathrm{c}$.

27. Кремнистые породы СССР / под ред. У.Г. Дистанова. - Казань: Тат. кн. Изд-во, 1976. -412 с.

28. Ресурсы и геохимия подземных вод Карелии / под ред. В.С. Самарина. - Петрозаводск: Карельский филиал АН СССР, 1987. $-151 \mathrm{c}$.

29. Перечень рыбохозяйственных нормативов: предельно допустимых концентраций (ПДК) и ориентировочно безопасных уровней воздействия (ОБУВ) вредных веществ для воды водных объектов, имеющих рыбохозяйственное значение. - М., Изд-во ВНИРО, 1999. - 304 с.

Поступила 29.01.2020 г.

\section{Информация об авторах}

Феоктистов B.M., кандидат химических наук, доцент кафедры общей химии Института биологии, экологии и агротехнологий Петрозаводского государственного университета.

Медведев П.В., кандидат геолого-минералогических наук, старший научный сотрудник Института геологии Карельского научного центра РАН; доцент кафедры наук о Земле и геотехнологий Института лесных, горных и строительных наук Петрозаводского государственного университета. 
UDC 550.4.02

\title{
TRACE ELEMENT COMPOSITION OF AQUEOUS EXTRACTS OF SOME DIATOMITE AND LYDITE SAMPLES FROM KARELIA
}

\author{
Vladimir M. Feoktistov', \\ feoktistov@petrsu.ru \\ Pavel V. Medvedev1,2, \\ pmedved@krc.karelia.ru \\ 1 Petrozavodsk State University, \\ 33, Lenin avenue, Petrozavodsk, 185910, Russia. \\ 2 Karelian Research Centre of RAS, \\ 11, Pushkinsky street, Petrozavodsk, 185910, Russia.
}

The relevance of the research consists in the necessity to obtain reliable information on microelemental composition of aqueous extracts of diatomite and lydite. Currently, diatomites are expected to be widely used in medical, pharmaceutical and food industries, but a detailed study of their composition has not been conducted.

The main aim of the research is to investigate the trace element composition of aqueous extracts of several samples of diatomite and lydite using ICP MS analytic method.

The objects: three samples of diatomite and two samples of lydite from Karelia (North-West of Russia).

Methods: grinding samples of diatomite and lydite infused with deionized water at room conditions. Assays of aqueous extracts of the studied samples were centrifuged and analyzed by ICP MS after 1, 3 and 10 days.

Results. The authors present the results of 54 chemical elements identification in water extracts of diatomite and lydite using ICP MS. In all water extracts $\mathrm{Mg}, \mathrm{Na}, \mathrm{Ca}, \mathrm{K}$ and $\mathrm{Al}$ (up to several thousand $\mu \mathrm{g} / \mathrm{l}$ ) are the predominant elements. Extracts of diatomite samples have a more homogeneous composition. The most important elements were: $P$ - 650, Fe - 1700 (sample no. 1) and Mn - up to 3300 (sample no. 3) $\mu \mathrm{g} / \mathrm{L}$. Concentrations in the range from 10 to $100 \mu \mathrm{g} / \mathrm{l}$ are typical for a number of elements (Li, B, Ti, Cr, Co, Ni, Cu, Zn, Sr, Y, Zr and $\mathrm{Ba}$ ) of all diatomite samples. Extracts of diatomite samples no. 1 and 2 had a maximum concentration of light REE: Nd (up to $247 \mu \mathrm{g} / \mathrm{l})$, Ce (up to $230 \mu \mathrm{g} / \mathrm{l})$, La (up to $156 \mu \mathrm{g} / \mathrm{l})$. Chemical composition of extracts of lydite was differed markedly, both among themselves and from diatomites. Acidic medium ( $\mathrm{pH} 4,5-4,6)$ of an aqueous extract of the sample lydite no. 4 contributed to accumulation of a number of elements Sr, Mn, U and, especially, Be, Fe, Co, Ni, Cu, Zn, Y, Ba, Tl. At the same time, maximum concentrations of V, Mo, W, Zr, Hf were observed in the extract of sample no. 5 under slightly alkaline conditions ( $\mathrm{pH} 7,4-7,5)$. We noted an excess of permissible limits of fishery water bodies for $\mathrm{Al}$ and $\mathrm{Mn}$ in all samples. The excess of the "normal» maximum permissible concentrations have also shown the transition elements ( $\mathrm{Fe}, \mathrm{Co}, \mathrm{Ni}, \mathrm{Cu}, \mathrm{Zn}$ ) in extracts of diatomite and sample lydite no. 4, as well as $\mathrm{V}$ and $\mathrm{Mo}$ in the sample lydite no. 5. The study of aqueous extracts of diatomite and lydites showed that diatomite and lydites under certain conditions can have a significant impact on composition of low-mineralized waters in the territory of Karelia. At the same time, the presence of useful elements for the plant growth (Mg, Ca, K, Cu, Zn, V, Mn, Sr, Y, Zr) gives the possibility of their use as a «soft» fertilizers (or additives to mineral fertilizers).

\section{Key words:}

Diatomite, Iydite, trace element composition, water extracts, Karelia, Paleoproterozoic, Holocene.

The authors are grateful to T.S. Shelekhova, senior researcher of the Institute of Geology, Karelian Research Centre of RAS, for courtesy of samples of diatomite and A.S. Paramonov, leading physicist of the Analytical center of the Institute of Geology, Karelian Research Centre of RAS, for performing ICP-MS analyzes.

The research was carried out within the state task of the Institute of Geology KarNC RAS.

\section{REFERENCES}

1. Demidov I.N., Shelekhova T.S. Diatomity Karelii (osobennosti formirovaniya, rasprostraneniya, perspektivy ispolzovaniya) [Diatomites of Karelia (features of formation, dissemination, and prospects for use)]. Petrozavodsk, Karelia Scientific center RAN Publ., 2006. 89 p.

2. Smirnov P.V. Results of complex studies of the material composition of diatomites of the Irbit Deposit. Bulletin of the Tomsk Polytechnic University. Geo Assets Engineering, 2016, vol. 327, no. 6. pp. 93-104.

3. Lu J., Sun B., Jin J., Jiang W. Mechanical and slow-released property of poly(acrylamide) hydrogel reinforced by diatomite. Materials Science and Engineering, 2019, vol. 99, pp. 315-321.

4. Wu W.-L., Chen Z. Modified-diatomite reinforced rubbers. Materials Letters, 2017 vol. 209, pp. 159-162.

5. Wu Y., Li X., Yang Q., Wang D., Huang X. Hydrated lanthanum oxide-modified diatomite as highly efficient adsorbent for low- concentration phosphate removal from secondary effluents. Journal of Environmental Management, 2019, vol. 231, pp. 370-379.

6. Benayache S., Alleg S., Mebrek A., Suñol J.J. Thermal and microstructural properties of paraffin/diatomite composite. Vacuиm, 2018, vol. 157, pp. 136-144.

7. Konuklu Y., Ersoy O., Erzin F., Toraman Y.Ö. Experimental study on preparation of lauric acid/microwave-modified diatomite phase change material composites. Solar Energy Materials and Solar Cells, 2019, vol. 194, pp. 89-94.

8. Wang K., Tang Z., Wu W., Xi P., Chen Sh. Nanocomposites CoPt$\mathrm{x} /$ Diatomite-C as oxygen reversible electrocatalysts for zinc-air batteries: Diatomite boosted the catalytic activity and durability. Electrochimica Acta, 2018, vol. 284, pp. 119-127.

9. Deng L., Du P., Yu W., Yuan P., Zhou J. Novel hierarchically porous allophane/diatomite nanocomposite for benzene adsorption. Applied Clay Science, 2019, vol. 168, pp. 155-163.

10. Rabie A.M., Shaban M., Abukhadra M.R., Hosny R., Negm N.A. Diatomite supported by $\mathrm{CaO} / \mathrm{MgO}$ nanocomposite as heterogene- 
ous catalyst for biodiesel production from waste cooking oil. Journal of Molecular Liquids, 2019, vol. 279, pp. 224-231.

11. Markov K.K. Diatomit. Poleznye iskopaemye Leningradskoy oblasti i Karelskoy ASSR. Spravochnik. Ch. II [Diatomite. Handbook. Minerals of the Leningrad region and the Karelian ASSR. P. II]. Leningrad, Gorgeoneftizdat Publ., 1933. pp. 67-85.

12. Vardanyants P.A. Diatomity severnoy Karelii. Materialy po geologii i poleznym iskopaemym Karelii [Diatomites of Northern Karelia. Materials on Geology and minerals of Karelia]. Moscow; Leningrad, ONTI NKTP SSSR Publ. 1936. pp. 83-93.

13. Gronlund T. Diatomite deposit in the basin of Lake Soijarvi, central Finland. Bull. Geo.Soc. Finland, 1986, vol. 58, P. 2, pp. 35-45

14. Distanov U.G. Opal-kristobalitovye porody [Opal-cristobalite rocks]. Mineralnoe syre. Spravochnik [Mineral raw materials. Handbook]. Moscow, Geoinformmark Publ., 1998. 28 p.

15. Ofitserov E.N., Ryabov G.K., Ubaskina Yu.A., Klimovskiy A.B., Fetyukhina E.G. Vliyanie opal-kristabolitovykh porod na soderzhanie rastvorimykh form kremnezema $\mathrm{v}$ prirodnykh vodakh [Influence of opal-cristobalite rocks on the content of soluble forms of silica in natural waters]. Izvestiya Samarskogo nauch nogo centra RAN, 2011, vol. 13, no. 4 (2), pp. 558-563.

16. Melezhik V.A., Fallick A.E., Filippov M.M., Larsen O. Karelian shungite - an indication of 2,0-Ga-old metamorphosed oil-shale and generation of petroleum: geology, lithology and geochemistry. Earth Sci. Rev., 1999, vol. 47, pp. 1-40.

17. Melezhik V.A., Fallick A.E., Filippov M.M., Deines Y.E., Črne A.E., Lepland A., Brasier A.T., Strauss H. Giant Palaeoproterozoic petrified oil field in the Onega Basin. Reading the Archive of Earth's Oxygenation. V. 3: Global Events and the Fennoscandian Arctic Russia - Drilling Early Earth Project. Eds. V.A. Melezhik, A.R. Prave, A.E. Fallick, L.R. Kump, H. Strauss, A. Lepland, E.J. Hanski. Heidelberg, New York, Dordrecht, London, Springer, 2013. pp. 1202-1212.

18. Vinogradov N.V. Vozmozhnost modifikatsii poverkhnosti minerala lidita perekhodnymi metallami [The possibility of modifying the surface of the mineral lyddite transition metals]. Problemy geologii $i$ osvoeniya nedr. Trudy XIX Mezhdunarodnogo simpoziuma studentov i molodykh uchenykh [Problems of Geology and Subsurface Development: Proc. of the $18^{\text {th }}$ International Scientific Symposium of students, Postgraduates and young Scientists]. Tomsk, Tomsk Polytechnic University Publ. house, 2015. Vol. II, pp. 250-252.

19. Atlas tekstur $i$ struktur shungitonosnykh porod Onezhskogo sinklinoria [Atlas of textures and structures of shungite-bearing rocks of Onega synclinore]. Eds. M.M. Filippov, V.A. Melezhik. Petrozavodsk, Karelian Research Centre of RAS, 2007. 80 p.

20. Khvorova I.V., Dmitrik A.P. Mikrostruktury kremnistykh porod [The microstructure of siliceous rocks]. Moscow, Nauka Publ., 1972. $170 \mathrm{p}$.

\section{Information about the authors}

Vladimir M. Feoktistov, Cand Sc., associate professor, Petrozavodsk State University.

Pavel V. Medvedev, Cand Sc., associate professor, Petrozavodsk State University; senior researcher, Karelian Research Centre of RAS.
21. Melezhik V.A., Filippov M.M., Romashkin A.E. A giant Palaeoproterozoic deposit of shungite in NW Russia: genesis and practical applications. Ore Geol. Rev., 2004, vol. 24, pp. 135-154.

22. Filippov M.M., Dejnes Yu.E. Subplastovy tip mestorozhdeniy shungitov Karelii [Subsheet type deposits of shungites of Karelia]. Petrozavodsk, KarNC RAN Publ., 2018. 261 p.

23. Diatomite. Subsurface use department. 2014. Available at: http://nedrark.karelia.ru/mnia/diatomit_karelia.htm (accessed 15 January 2020).

24. Feoktistov V.M., Vapirov V.V., Chazhengina S.Yu., Svetov S.A. Osobennosti khimicheskogo sostava prirodnykh kremnevykh konkretsiy i ikh vodnykh ekstraktov [Specific features of chemical composition of natural chert nodules and their aqueous extracts]. Ekologicheskaya khimiya, 2019, vol. 28, no. 1, pp. 10-21.

25. Rukovodyashchiy dokument RD 52.24.433-2005. Massovaya kontsentratsiya kremniya $v$ poverkhnostnykh vodakh sushi. Metodika vypolneniya izmereniy fotometricheskim metodom $v$ vide zheltoy formy molibdokremnievoy kisloty [Guidance document RD 52.24.433-2005. Mass concentration of silicon in surface waters of land. The method of measurement by photometric method in the form of a yellow form of molybdenum-silicic acid]. Rostov-ondon, Hydrochemical Institute Publ. house, 2005. 15 p.

26. Rukovodyashchiy dokument RD 52.24.495-2005. Vodorodny pokazatel $i$ udelnaya elektricheskaya provodimost vod. Metodika vypolneniya izmereniy elektrokhimicheskim metodom [Guidance document RD 52.24.495-2005. Hydrogen index and specific electrical conductivity of water. Methods of measurement by electrochemical method]. Rostov-on-don, Hydrochemical Institute Publ. house, $2005.10 \mathrm{p}$.

27. Kremnistye porody SSSR [Siliceous rocks of the USSR]. Ed. by U.G. Dystanova. Kazan, Tat. Publ. House, 1976. 412 p.

28. Resursy i geokhimiya podzemnykh vod Karelii [Resources and geochemistry of underground waters of Karelia]. Ed. by V.S. Samarin. Petrozavodsk, Karelian Branch of USSR Academy of Science Publ., 1987. 151 p.

29. Perechen rybokhozyaystvennykh Normativov: predelno dopustimykh kontsentratsiy $(P D K)$ and orientirovochno bezopasnykh urovney vozdeystviy (OBUV) vrednykh veshchestv dlya vody vodnykh obektov, rybokhozyaystvennogo znacheniya [Standards of water quality of water bodies of fishery value, including standards of maximum permissible concentrations of harmful substances in waters of water bodies of fishery value.]. Moscow, VNIRO Publ., 1999. 304 p.

Received: 29 January 2020. 